\title{
Carotid intima-media thickness is associated with cognitive deficiency in hypertensive patients with elevated central systolic blood pressure
}

Eros da Mota Dias', Luiz Tadeu Giollo Jr ${ }^{1}$, Débora Dada Martinelli ${ }^{1}$, Camila Mazeti ${ }^{1}$, Heitor Moreno Júnior ${ }^{2}$, José Fernando Vilela-Martin ${ }^{1}$ and Juan Carlos Yugar-Toledo ${ }^{1 *}$

\begin{abstract}
Background: The role of hypertension in the loss of cognitive function is controversial. Relationships between hypertension and increases in cerebral vascular resistance, diffused lesions and multiple lacunar infarcts of the white matter are well known. Thus, the objectives of this study were: to evaluate the relationship between hypertension and cognitive dysfunction (CD), identify risk factors and determine the association between early markers of vascular disease and CD in hypertensive individuals.

Methods: Two hundred individuals aged between 40 and 80 years old were evaluated in this cross-sectional prospective study. Fifty participants were controls (CT). The remaining 150 hypertensive patients were subdivided into two groups, those with CD (HCD) and those without CD (HNCD). All participants underwent clinical evaluations and biochemical blood tests were performed. CD was investigated using the Mini Mental State Examination (MMSE) following the guidelines for its use in Brazil. The impact of hypertension on the arterial bed was assessed by identifying and measuring changes in the intima-media thickness (IMT) by vascular ultrasonography of the carotid arteries and analyses of the central blood pressure and Augmentation Index by applanation tonometry of the radial artery.

Results: There were no significant differences in the total cholesterol, high-density lipoprotein cholesterol and triglycerides plasma concentrations between the three groups. The serum creatinine and estimated glomerular filtration rate were within normal ranges for all three groups. A significantly lower MMSE score was recorded for the HCD Group compared to the HNCD and CT Groups ( $p$-value < 0.05).

The IMT was significantly different between the HNCD and HCD Groups ( $p$-value $=0.0124)$. A significant difference in the IMT was also observed between hypertensive patients and the CT Group (p-value < 0.0001). Age, low-density cholesterol, high-density cholesterol, triglycerides and IMT increased the Odds Ratio for cognitive dysfunction. The central systolic pressure was significantly higher in the HCD and HNCD Groups compared to CT Group ( $p$-value $<0.0001$ ).
\end{abstract}

Conclusions: Hypertensive patients with CD have changes in the vascular morphology characterized by an increased carotid IMT, enhanced atherosclerotic lipid profile and impaired hemodynamic functional manifested by elevated central systolic blood pressure.

Keywords: Hypertension, Cognitive impairment, Intima-media thickness, Central systolic blood pressure

\footnotetext{
*Correspondence: yugarjuan@uol.com.br

${ }^{1}$ Hypertension Clinic, Department of Internal Medicine, State Medical School of São José do Rio Preto (FAMERP), Rua: Las Vegas 200, São José do Rio Preto, SP CEP 15093-010, Brazil

Full list of author information is available at the end of the article
} 


\section{Introduction}

Hypertension is a major risk factor for cardiovascular disease including strokes (especially hemorrhagic), coronary heart disease (myocardial infarction) [1-3], left ventricular hypertrophy, congestive heart failure [4-6], aortic dissection [7-9], renal failure [10-12] and peripheral vascular disease [13]. Acute myocardial infarction and strokes are associated with high mortality rates in adulthood, particularly in the elderly [14-16].

Cognitive deficiency (CD) is considered a form of dementia and defined as a "persistent or permanent decline in varying dimensions of intellectual function in a way that it interferes with the individual's normal social or economic activities. Currently, the Diagnostic and Statistical Manual of Mental Disorders defines dementia as an 'organic brain syndrome' (American Psychiatric Association, 1994); this is mainly to differentiate it from other cognitive function disorders such as mental retardation and reversible episodes of amnesia or other changes in focal elements of cognitive components such as language disorders $[17,18]$.

The role of hypertension in determining the loss of cognitive function is not well defined $[19,20]$. It is well known that hypertension is associated to increased cerebral vascular resistance with diffuse lesions and multiple lacunar infarcts in the white matter (especially in the subcortical region) that are histopathologically detectable and visible by magnetic resonance imaging [21-23]. Such infarcts have been linked to dementia in the elderly [24]. With the current scientific and technological progress, more accurate diagnostic tests such as positron emission tomography allow a better understanding of changes in human brain structures related to hypertension, as do animal experiments, which allow a histopathological view of similar lesions [25-29]. Thus, vascular risk factors may impair cognitive function and are linked not only to vascular dementia but also to Alzheimer's disease. The level of evidence for these associations is highest for hypertension and diabetes mellitus, especially when these factors are found in middle-aged individuals [30].

The effect of antihypertensive treatment on the cognitive function in older adults is also controversial. Some studies suggest that treatment improves cognitive function while others found no effect or even the opposite effect [31-34]. In general, research has difficulty in distinguishing the true influence of hypertension on cognition as the effect of antihypertensive medications must be taken into account [35-38]. This is because of several reasons; in general, adequate blood pressure (BP) control is not achieved with the treatment regimens both due to non-adherence to treatment and due to the inappropriate choice of antihypertensive medications. It is well known that hypertension should be treated with drug combinations when the desired effect of a drop in BP is not attained with a single medication $[39,40]$.

Thus, the objectives of this study were to evaluate the relationship between hypertension and $\mathrm{CD}$, to identify risk factors associated to the development of $\mathrm{CD}$ (gender, age, education, body mass index (BMI), dyslipidemia, diabetes and chronic kidney disease) and to determine associations between different early markers of vascular disease (carotid intima-media thickness, vascular elasticity and rigidity, and central arterial pressure) and $C D$ in hypertensive individuals on regular antihypertensive treatment.

\section{Patients and methods}

The sample population of this prospective study consisted of two hundred consecutive male and female individuals aged between 40 and 80 years old selected in the specialized hypertension center of the Medicine School in São José do Rio Preto (FAMERP). All participants were submitted to ultrasound assessment and the Mini Mental State Examination between February 2009 and October 2011. Of these, one hundred and fifty were stage II hypertensive patients according to JNC VII [39]; Forty-two hypertensive patients had CD (HCD group) and one hundred and eight hypertensive patients had no CD (HNCD group).

The Control Group (CT), made up of non-hypertensive, non-cognitive dysfunction individuals, was selected from subjects referred to investigate stage I primary hypertension but whose blood pressures proved to be normal after standard measurements in the physical examination and whose biochemical blood tests were normal.

This study was approved by the Research Ethics Committee of the Post Graduation Program in Health Sciences of the Medicine School in São José do Rio Preto (FAMERP). Informed written consent was obtained from all participants before their enrollment in the study. The sample size was estimated based on an $80 \%$ statistical power to demonstrate the objectives of the study with a type I alpha error rate of $5 \%$.

The inclusion criteria of the hypertensive patients were: age between 40 and 80 years under treatment for stage II hypertension - VII JNC, optimal response to pharmacological treatment $(\mathrm{BP}<140 / 90 \mathrm{mmHg})$ with no acute medical illness in the previous month and the ability to understand, verbalize and answer questions related to the study. The exclusion criteria were the presence of atherosclerotic plaque defined as a focal structure that encroaches into the arterial lumen by at least $0.5 \mathrm{~mm}$ or $50 \%$ of the surrounding IMT or demonstrates a thickness $>1.5 \mathrm{~mm}$ as measured from the media-adventitia interface to the intima-lumen interface. 
Participants were submitted to clinical evaluations, physical examinations and investigations of their family history for cardiovascular disease. Blood pressure of the right arm was measured during the morning by a trained healthcare professional with the patient in the seated position and using an appropriately sized cuff.

The age, gender, weight, height, and the results of an electrocardiogram and biochemical blood tests were recorded. Patients with secondary hypertension, those taking anticholinesterase drugs, those that had suffered strokes, had diagnosis of dementia or had recently had an acute infection were excluded in order to rule out the possibility of acute confusional state. Additionally, patients with family history of Alzheimer's disease (parents and siblings), or history of psychiatric illness or substance abuse were excluded.

\section{Mini-mental state examination}

The Mini-Mental State Examination (MMSE) is a test that uses two specific types of responses, verbal and nonverbal, to identify cases of CD. Diagnosis of dementia or any specific dementing illness is not an objective of this test. Responses to questions are studied through verbal sub-tests that measure time-space orientation, immediate memory, attention and calculation, and recall and language and nonverbal subtests that assess perceptual-motor coordination and comprehension of instructions. The test quantifies responses through simple, easy to use criteria that are compatible with the application. Administration of the test takes about 5 to 10 minutes by duly trained professionals. The test is dependent on the level of education of the interviewee. The MMSE results in a maximum score of 30 points where the lower the score, the greater the CD with 24 points originally being considered as the cutoff point [41-46].

\section{Blood pressure measurements}

The starting point to evaluate hypertension is the accuracy of the BP measurement. The average of three measurements of the systolic blood pressure (SBP) and diastolic blood pressure (DBP) were recorded. Measurements were made by the indirect technique using OMRON equipment and employing cuffs with appropriate dimensions for the perimeter of the arm (a widthlength ratio of 1:2). The readings were taken after the patient had remained resting in the seated position with the arm on a support at the same height as the apex in a quiet environment for 5 to 15 minutes, at least $60 \mathrm{~min}$ utes after the ingestion of coffee and 30 minutes after smoking. BP analyses were performed at least three times with an interval of five minutes between readings and the mean of measurements was calculated.

\section{Carotid intima-media thickness}

The carotid intima-media thickness (IMT), the mean thickness of the anterior and posterior walls of the left and right carotid arteries, was evaluated using high resolution ultrasound. Patients were always examined between 7:00 a.m. and 11:00 a.m. in the supine position with the head at a $45^{\circ}$ angle on a support.

This method is established and standardized according to the " $34^{\text {th }}$ Report of the Bethesda Conference Task Force \#3 Noninvasive Atherosclerosis Measurement" [47] using a sample protocol outlined by the American Society of Echocardiography [48].

The ultrasound analysis was performed by a physician experienced in vascular studies and certified by the Cardiovascular Imaging Department of the Brazilian Society of Cardiology and blinded to the patient's clinical data. The examination was carried out according to a previously established protocol [49] standardized for both carotid arteries. Images were acquired at end diastole (defined as the $\mathrm{R}$ wave of the electrocardiogram) using a 7-12 $\mathrm{MHz}$ linear transducer and high resolution ultrasound (Philips, HD $11 \mathrm{XE}$, Andover MA - USA). The intima-media thickness was measured over a $1-\mathrm{cm}$ segment of the artery located approximately $0.5 \mathrm{~cm}$ below the carotid-artery bulb and considered not to contain any plaque (i.e., not to have any perceivable protrusion of the artery wall into the lumen) [50,51].

The IMT data were analyzed offline by two independent observers by computer program analysis (M'ATh Metris, France) which allows measurement of the IMT from images obtained during four cardiac cycles identified by the $\mathrm{R}$ wave of the ECG. The analysis, based on the tone of the gray scale and a specific algorithm to recognize tissue, is automatic. The average measurements of the near and far walls of the left and the right common carotid arteries were used to compare the results between the three study groups. The variability between IMT measurements should be less than $2 \%$, as in this study.

\section{Radial artery tonometry and central systolic blood pressure}

Central (aortic and carotid) blood pressures are more strongly related to the pathogenesis of cardiovascular disease than peripheral pressures [52]. It is the aortic systolic pressure that the left ventricle encounters during systole (afterload), and the aortic pressure during diastole is a determinant of coronary perfusion. Furthermore, the distending pressure in the large elastic-type arteries (aorta and carotid) is a key determinant of the degenerative changes that characterize accelerated aging and hypertension. In contrast, muscular peripheral arteries, such as the brachial and radial arteries, are less influenced by these changes [53]. 
Because of pulse pressure amplification between central and peripheral arteries, it is inaccurate to use the brachial pulse pressure as a surrogate for carotid or aortic pulse pressure, particularly in young subjects. The carotid femoral Pulse Wave Velocity (PWV) is considered the "gold standard" measurement of arterial stiffness. Pulse-wave analysis should be obtained at the central level, i.e. at the site of the carotid artery or the ascending aorta, and either directly recorded or computed from the radial artery waveform using a transfer function. The pulse waveform should be analyzed by three major parameters: central pulse pressure, central systolic blood pressure and augmentation index [54].

Arterial stiffness is one of the determinants of increased pulse pressure (PP) and central BP, which are considered predictors of cardiovascular risk.

Tonometry of the radial artery provides an accurate, reproducible, noninvasive assessment of the central PP waveform. Radial artery applanation tonometry (AT) is performed by placing a hand-held tonometer (strain gauge pressure sensor) over the radial artery and applying mild pressure to partially flatten the artery. The radial artery pressure is then transmitted from the vessel to the sensor (strain gauge) and is recorded digitally. A mathematical formula using a fast Fourier transformation algorithm, approved by the Food and Drug Administration of the USA, permits derivation and calculation of central systolic blood pressure indices from a peripheral brachial blood pressure with concomitant recording of a PP wave with radial AT. This provides information on the functional condition of arteries by the Augmentation Index, which calculates the ratio of the reflected wave and the ejection wave [51]. The premise states that the speed at which these waves travel increases as the rigidity of the arterial wall increases. Thus, endothelial disorders with reduced function can be detected early by the AT system [55-58].

The examination to evaluate the AT was made with the patient in a quiet environment, after resting for at least 5 minutes, sitting with the legs uncrossed and the bladder empty, away from acute stressors, without having drunk alcoholic beverages and without having smoked for at least 30 minutes. The OMROM AT equipment with a radial ultrasound transducer was employed with cuffs of suitable dimensions and correct proportion for the arm circumference.

\section{Statistical analysis}

Descriptive statistics were performed to describe the sample in relation to demographic and clinical characteristics. Means, standard deviation and 95\% confidence interval were calculated for all variables. Antihypertensive drugs by class (Hydrochlorothiazide, ACE-inhibitors, Angiotensin type 2 receptor blockers, Beta-blockers and Calcium channel blockers) were entered as binary values.

For the analysis of quantitative parameters, the $t$-test and Mann-Whitney test were used to compare aspects of hypertensive patients with or without changes in cognitive function and control individuals. The chi-square test and proportions were adopted for qualitative variables.

Analysis of variance (ANOVA) was used to compare the mean of the carotid intima thickness, central SBP and Augmentation Index between the three groups.

Logistic regression, with the STATA 12.1 statistics program (Stata Corp LP, College Station, Texas, USA), was used to determine if independent variables can predict the outcome, in this case CD (the dependent variable). The independent variables were the clinical and demographic variables including, age, gender, BMI, blood sugar levels, total cholesterol, LDL cholesterol, HDL cholesterol, triglycerides, creatinine, estimated glomerular filtration rate, microalbuminuria, 24-hour urinary sodium excretion, systolic blood pressure, diastolic blood pressure, pulse pressure, mean blood pressure, augmentation index (Ai75), central systolic blood pressure (CSBP) and carotid IMT. Statistical significance was set for a $\mathrm{p}$-value $<0.05$.

\section{Results}

There were statistically significant differences between the groups in respect to age (HCD, HNCD vs. CT - pvalue $<0.0001 ; \mathrm{HCD}$ vs. HNCD - p-value $=0.0017)$ and BMI (HCD vs. CT - p-value <0.0001; HNCD vs. CT - pvalue $<0.0001)$. No significant differences were found between the two hypertensive subgroups in relation to the duration of hypertension $(\mathrm{HCD}=15.03 \pm 9.74$ vs. HNCD $15.73 \pm 9.57$ - p-value $=0.40$ ) and in relation to the use of different anti-hypertensive drug classes (Table 1).

The mean values of SBP, DBP, MAP and PP in the HCD and HNCD groups measured during outpatient visits were all higher than in the CT group. There were statistically significant differences for the SBP and PP of the HCD and HNCD groups versus the CT group (pvalue $<0.001)$. There was no statistically significant difference for DBP and heart rate (HR) comparing the three groups (Table 2).

The biochemical values of the three groups are described in Table 3.

The results of the MMSE for the three groups (HCD, HNCD and CT) expressed as means \pm standard deviation are summarized in Table 4. A significantly lower MMSE score was found for the HCD group compared to the HNCD and CT groups (Figure 1).

The logistic regression analysis of risk factors for predictive effect on $\mathrm{CD}$ in hypertensive patients (age, 
Table 1 Demographic and anthropometric characteristics of the HCD, HNCD and CT groups

\begin{tabular}{|c|c|c|c|}
\hline & HCD & HNCD & CT \\
\hline Age (years) & $63.22 \pm 9.3^{*}$ & $55.75 \pm 8.66^{*}$ & $44.56 \pm 7.93$ \\
\hline Gender: F/M & $26 / 16$ & $58 / 50$ & $30 / 18$ \\
\hline Height & $1.62 \pm 0.11$ & $1.65 \pm 0.09$ & $1.63 v 0.24$ \\
\hline weight & $75.56 \pm 15.95$ & $80.69 \pm 16.18$ & $71.58 \vee 18.25$ \\
\hline BMI $\left(\mathrm{kg} / \mathrm{m}^{2}\right)$ & $29.04 \pm 6.81 *$ & $29.57 \pm 5.2^{*}$ & $25.83 \pm 4.91$ \\
\hline Duration HBP & $15.03 \pm 9.74$ & $15.73 \pm 9.57$ & - \\
\hline Number of $A-H$ & $2.43 \pm 0.97$ & $2.35 \pm 0.85$ & \\
\hline HCT & $36(86 \%)$ & 85 (79\%) & \\
\hline ACEI & $22(52 \%)$ & $53(49 \%)$ & \\
\hline ARB & $15(36 \%)$ & $45(42 \%)$ & \\
\hline BB & $16(38 \%)$ & $40(37 \%)$ & \\
\hline CCB & $13(31 \%)$ & $31(29 \%)$ & \\
\hline$n$ & 42 & 108 & 48 \\
\hline \multicolumn{4}{|c|}{$\begin{array}{l}\text { Values expressed as means } \pm \text { standard deviation or } n(\%) \text {. } \\
n \text { number of individuals, } H C D \text { hypertensive with cognitive deficiency, HNCD } \\
\text { hypertensive without cognitive deficiency, } C T \text { controls, BMI body mass index, } \\
M \text { male, } F \text { female, HBP high blood pressure. } \\
A-H \text { Anti-hypertensive drugs, } H C T \text { Hydrochlorothiazide, } A C E I \text { Angiotensin } \\
\text { Converting Enzyme Inhibitor, } A R B \text { Angiotensin Type } 2 \text { Receptor Blocker, } B B \\
\text { beta blocker, CCB Calcium Chanel Blocker. } \\
{ }^{*} \text { p-value }<0.0001 \text { HCD-HNCD vs. CT. }\end{array}$} \\
\hline
\end{tabular}

gender, height, weight, BMI, blood sugar levels, total cholesterol, HDL cholesterol, LDL cholesterol, triglycerides, creatinine, estimated glomerular filtration rate, microalbuminuria, and 24-hour urinary sodium excretion) showed that only age HDL cholesterol, LDL cholesterol, triglycerides and increased IMT were associated with increased odds ratios (OR) in hypertensive patients with declines in MMSE scores (Table 5 and Figure 2).

The results of carotid IMT measurement in the three groups (HCD, HNCD and CT) are shown in Figure 3. The HCD group had a significantly greater IMT compared to the CT group $(0.99 \pm 0.2 \mathrm{~mm}$ versus $0.69 \pm$ $0.1 \mathrm{~mm}$, respectively; p-value $<0.0001)$. Similarly, there was a statistically significant difference between the

Table 2 Hemodynamic characteristics of the HCD, HNCD and $C T$ groups

\begin{tabular}{|c|c|c|c|}
\hline & HCD & HNCD & $C T$ \\
\hline SBP $(\mathrm{mmHg})$ & $132.9 \pm 24.29 *$ & $128.4 \pm 16.66 t$ & $115.4 \pm 20.61$ \\
\hline $\mathrm{DBP}(\mathrm{mmHg})$ & $73.26 \pm 15.24$ & $73.65 \pm 13.32$ & $70.49 \pm 13.25$ \\
\hline MBP (mmHg) & $93.13 \pm 16.61$ & $91.90 \pm 13.12$ & $85.44 \pm 15.45$ \\
\hline $\mathrm{PP}(\mathrm{mmHg})$ & $59.61 \pm 18.41 *$ & $54.75 \pm 13.17 \dagger$ & $44.96 \pm 9.53$ \\
\hline HR (bpm) & $68.00 \pm 13.1$ & $71.91 \pm 11.29$ & $72.78 \pm 11.08$ \\
\hline$n$ & 42 & 108 & 48 \\
\hline \multicolumn{4}{|c|}{$\begin{array}{l}\text { Values expressed as means } \pm \text { standard deviation. } \\
n \text { number of individuals, } H C D \text { hypertensive with cognitive deficiency, } H N C D \\
\text { hypertensive without cognitive deficiency, } C T \text { controls, } S B P \text { systolic blood } \\
\text { pressure, } D B P \text { diastolic blood pressure, } M B P \text { mean blood pressure, } P P \text { pulse } \\
\text { pressure, } H R \text { heart rate. } \\
{ }^{*} \text { p-value }<0.0001 \mathrm{HCD} \text { vs. } C T ; \uparrow \text {-value }<0.002 \mathrm{HNCD} \text { vs. } C T \text {. }\end{array}$} \\
\hline
\end{tabular}

Table 3 Biochemical parameters of the HCD, HNCD and CT groups

\begin{tabular}{|c|c|c|c|}
\hline & $\mathrm{HCD}$ & HNCD & CT \\
\hline Glycemia (mg/dL) & $106.7 \pm 23.26$ & $116.9 \pm 42.71^{*}$ & $91.04 \pm 25.62$ \\
\hline $\begin{array}{l}\text { Total cholesterol } \\
\text { (mg/dL) }\end{array}$ & $186.9 \pm 36.59$ & $184.6 \pm 38.62$ & $201.9 \pm 44.82 \#$ \\
\hline $\begin{array}{l}\text { LDL cholesterol } \\
\text { (mg/dL) }\end{array}$ & $102.6 \pm 30.71$ & $96.62 \pm 28.96$ & $124.4 \pm 34.94$ \\
\hline $\begin{array}{l}\text { HDL cholesterol } \\
(\mathrm{mg} / \mathrm{dL})\end{array}$ & $57.68 \pm 12.59$ & $51.16 \pm 13.19$ & $54.28 \pm 14.37$ \\
\hline Triglycerides (mg/dL) & $159.5 \pm 12.91$ & $153.1 \pm 138.2$ & $121.1 \pm 58.31$ \\
\hline Creatinine (mg/dL) & $1.08 \pm 0.17+$ & $1.13 \pm 0.28+$ & $0.76 \pm 0.21$ \\
\hline eGFR & $70.14 \pm 21.77$ & $73.31 \pm 22.65$ & $98.16 \pm 18.9$ \\
\hline $\begin{array}{l}\text { Microalbuminuria } \\
\mathrm{mg} / 24 \mathrm{~h}\end{array}$ & $49.24 \pm 72.76$ & $64.60 \pm 202.7$ & $8.6 \pm 13.8$ \\
\hline Potassium (mEq/L) & $4.27 \pm 0.27$ & $4.28 \pm 0.42$ & $4.24 \pm 0.08$ \\
\hline $\begin{array}{l}24 \mathrm{~h} \text { Urinary Sodium } \\
(\mathrm{mEq} / 24 \mathrm{~h})\end{array}$ & $206.0 \pm 72.83 \neq$ & $204.2 \pm 80.82 \neq$ & $169.1 \pm 55.23$ \\
\hline $\bar{n}$ & 41 & 108 & 48 \\
\hline
\end{tabular}

HNCD and CT groups $(0.89 \pm 0.2 \mathrm{~mm}$ vs. $0.69 \pm$ $0.1 \mathrm{~mm}$, respectively; $\mathrm{p}$-value $<0.0001)$. On the other hand, we also observed statistically significant differences for the IMT between the HCD and HNCD groups (0.99 $\pm 0.2 \mathrm{~mm}$ vs. $0.89 \pm 0.2 \mathrm{~mm}$, respectively; $\mathrm{p}$-value $=$ $0.0124)$.

Table 6 shows the CSBP and Augmentation Index (Ai75) corrected for HR for the three groups (HCD, HNCD and CT) and Figure 4 shows the results of the measurement of the central SBP for the three groups (HCD, HNCD and CT). The CSBP was significantly higher for the HCD group compared to the CT group $(123.8 \pm 3.91 \mathrm{mmHg}$ vs. $105.5 \pm 2.0 \mathrm{mmHg}$, respectively; p-value $<0.0001)$. Similarly, there was a statistically significant difference between the HNCD group and the CT group $(118.5 \pm 1.58 \mathrm{mmHg}$ vs. $105.5 \pm 2.0 \mathrm{mmHg}$, respectively; p-value $<0.0001$ ). On the other hand, no significant difference was observed for the CSBP between the HCD and HNCD groups $(123.8 \pm 3.91 \mathrm{mmHg}$ versus $118.5 \pm 1.58 \mathrm{mmHg}$; $\mathrm{p}$-value $=0.245)$.

Table 4 Mini-Mental State Examination Score for the HCD, HNCD and CT groups

\begin{tabular}{lllc}
\hline Group & Mean & SD & $\mathbf{9 5 \% ~ C l}$ \\
\hline CT & 27.77 & 4.4 & $26.46-28.08$ \\
HNCD & 28.44 & 1.30 & $28.19-28.69$ \\
HCD & 22.02 & 2.4 & $21.27-22.78$ \\
\hline
\end{tabular}

$n$ number of individuals, $H C D$ hypertensive with cognitive deficiency, $H N C D$ hypertensive without cognitive deficiency, $C T$ controls SD standard deviation, 95\% Cl=95\% confidence interval. 


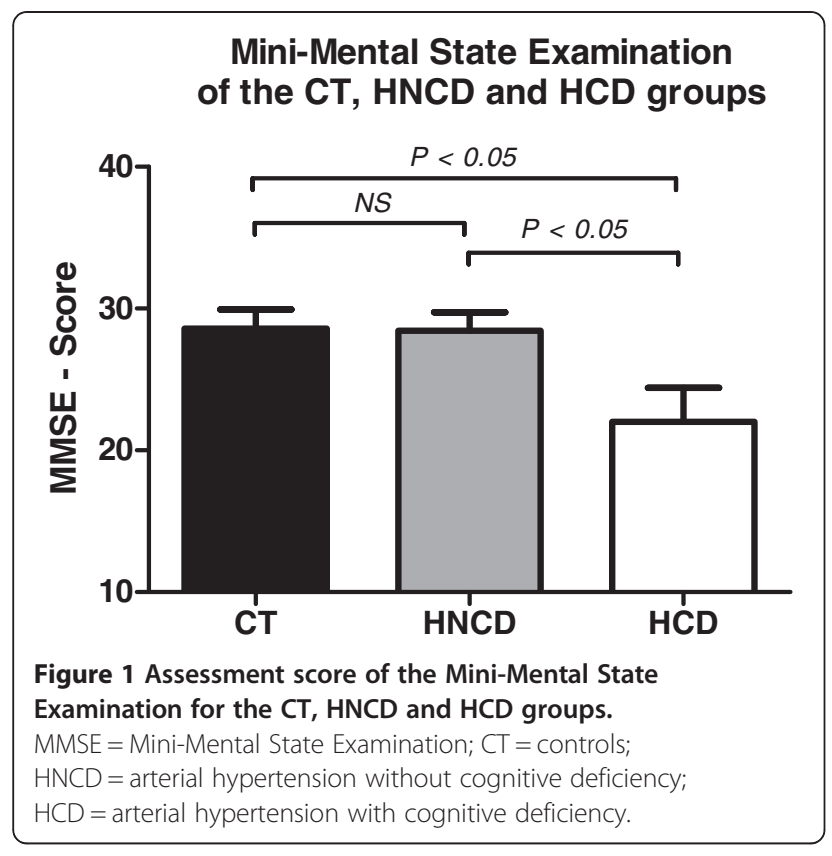

Table 5 Logistic regression, Odds Ratio (OR) and 95\% Confidence Interval $(\mathrm{Cl})$ for cognitive dysfunction in relation to cardiovascular risk factors

\begin{tabular}{lccccc}
\hline & Odds Ratio & SD & p-value & \multicolumn{2}{c}{$95 \%$ Cl } \\
\hline Age & 1.113 & 0.406 & $0.048^{*}$ & 1.043 & 1.181 \\
Gender & 1.339 & 0.673 & 0.562 & 0.499 & 3.587 \\
BMI & 0.975 & 0.044 & 0.580 & 0.891 & 1.066 \\
Glycemia & 0.971 & 0.158 & 0.075 & 0.941 & 1.003 \\
Total cholesterol & 0.860 & 0.487 & $0.007^{*}$ & 0.769 & 0.901 \\
LDL cholesterol & 1.173 & 0.669 & $0.005^{*}$ & 1.049 & 1.312 \\
HDL cholesterol & 1.163 & 0.676 & $0.009^{*}$ & 1.038 & 1.304 \\
Triglycerides & 1.128 & 0.010 & $0.006^{*}$ & 1.067 & 1.148 \\
Creatinine & 0.245 & 0.322 & 0.284 & 0.189 & 3.206 \\
eGFR & 0.978 & 0.108 & 0.215 & 0.944 & 1.013 \\
Microalbuminuria & 1.003 & 0.003 & 0.174 & 0.999 & 1.019 \\
24 h Urinary Sodium & 1.004 & 0.004 & 0.303 & 0.996 & 1.013 \\
SBP & 1.203 & 0.270 & 0.409 & 0.775 & 1.868 \\
DBP & 0.628 & 0.427 & 0.495 & 0.165 & 2.385 \\
PP & 0.737 & 0.232 & 0.335 & 0.397 & 1.369 \\
MBP & 1.337 & 0.837 & 0.643 & 0.391 & 4.564 \\
CSBP & 1.006 & 0.382 & 0.858 & 0.934 & 1.072 \\
Ai 75 & 1.021 & 0.255 & 0.392 & 0.972 & 1.072 \\
IMT & 1.128 & 0.002 & $0.041^{*}$ & 1.031 & 1.219 \\
\hline P-Vale & & & & &
\end{tabular}

${ }^{*}$ p-value $<0.05$.

$B M I$ body mass index, $L D L$ low-density lipoprotein cholesterol fraction, $H D L$ high-density lipoprotein cholesterol fraction, eGFR estimated glomerular filtration rate, SBP systolic blood pressure, DBP diastolic blood pressure, $P P$ pulse pressure, MBP mean blood pressure, CSBP central systolic blood pressure, $A i 75$ augmentation index at 75 beats per minute, IMT carotid intima media thickness.
There were no statistically significant differences in respect to the Augmentation Index (corrected for HR) between the three groups (HCD, HNCD and CT).

\section{Discussion}

The main results of this study show: 1) morphological changes characterized by an increased carotid IMT and functional changes qualified as an increase in central SBP in hypertensive patients with CD; 2) Among the risk factors for the development of $\mathrm{CD}$, the age, HDL cholesterol, LDL cholesterol, triglycerides and increased IMT were significantly associated with a drop in MMSE scores in hypertensive patients.

Several factors have been associated with loss of cognitive function in older adults. According to many studies the educational level is considered to be one of the most important determinants $[17,59,60]$ with less well educated individuals being more likely to have CD. Age has also been linked directly to a loss of cognitive function [61-65]. Other factors have also been mentioned in studies such as being female [66], smoking [67,68], atherosclerosis [69,70], diabetes mellitus $[17,71,72]$, family history of dementia [73] and low-income [17,74].

In this study, the atherosclerotic profile, confirmed by increases in LDL cholesterol, triglycerides and subclinical atherosclerosis characterized by increased carotid IMT were associated with higher ORs for cognitive dysfunction in hypertensive patients independently of the pharmacological antihypertensive treatment and the other risk factors for cardiovascular disease.

Elevation of LDL cholesterol levels increase the risk of cognitive dysfunction by $17 \%$ in hypertensive patients in agreement with a few previous reports that showed negative effects of the atherosclerotic lipid profile on the cognitive function in adults $[30,75]$.

On the other hand, epidemiological studies in Rotterdam, Netherlands, demonstrated a significant association between various cardiovascular risk factors including hypertension [76], cerebral white matter lesions and worse performance in neuropsychometric tests [59,60,75,77,78]. Additionally, Ikeda et al. [79], in an analysis of 76 untreated hypertensive patients, 173 treated hypertensive patients and 69 normotensive individuals, showed that the non-treated hypertensive subjects had a higher prevalence of asymptomatic cerebral lacunae at computed tomography compared to normotensive individuals. In this study, the severity and duration of hypertension had a direct correlation with cerebrovascular complications. Studies with large samples showed comparable findings. Liao et al. [79], for example, studied 1920 subjects using magnetic resonance imaging. Hypertension, smoking and age were associated with a higher prevalence of cerebral white matter lesions although the authors did not investigate possible 


\section{Logistic regresion for cognitive dysfunction}

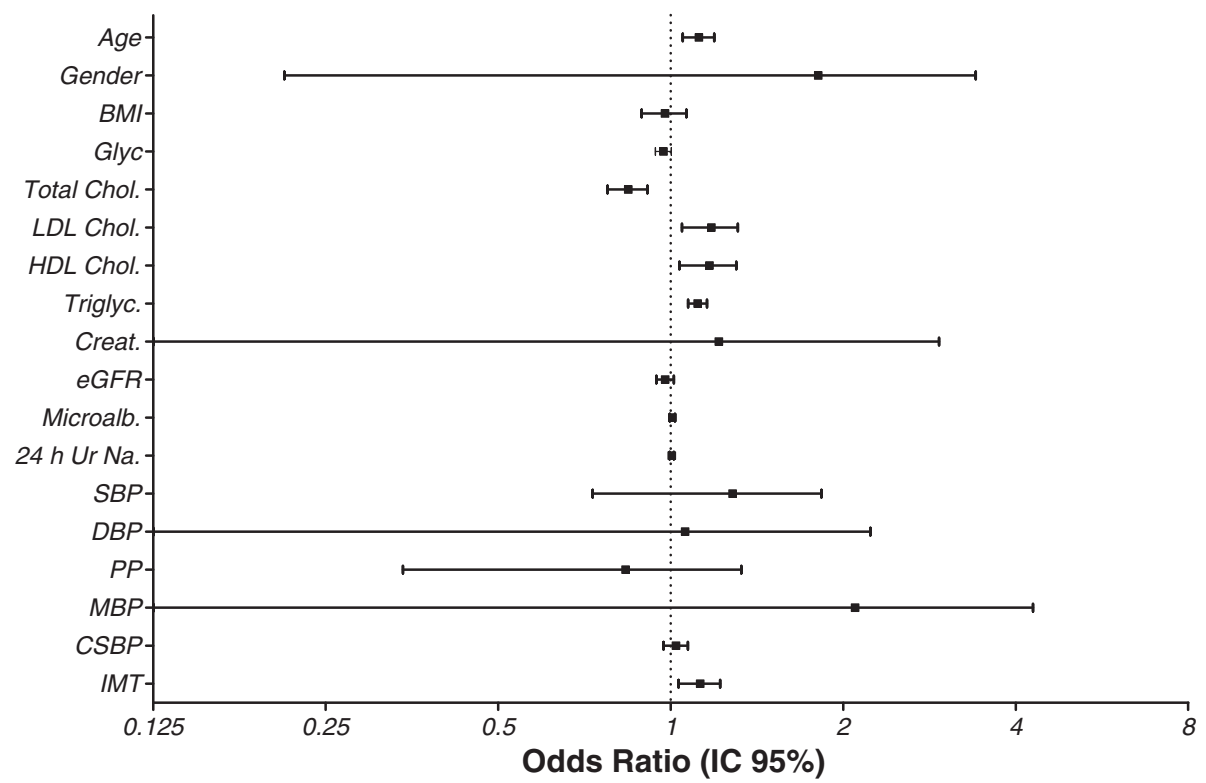

Figure 2 Logistic regression for event cognitive dysfunction in hypertensive patients. Odds Ratio (OR) and Confidence Interval 95\% (CI 95\%). BMI - body mass index; LDL - low-density lipoprotein cholesterol fraction; HDL - high-density lipoprotein cholesterol fraction; eGFR - estimated glomerular filtration rate; $\mathrm{SBP}=$ systolic blood pressure; $\mathrm{DBP}=$ diastolic blood pressure; $\mathrm{PP}=$ pulse pressure; $\mathrm{MBP}=$ mean blood pressure; CSBP = central systolic blood pressure; IMT = carotid intima-media thickness.

associations between these lesions and CD. Clinical and epidemiological studies also showed positive results in the analysis of this association. Starr et al. [31] in a cross-sectional study of 598 elderly, identified a lower mean MMSE score for individuals with high SBP compared to individuals with normal or low SBPs. Prince et al. [32] performed a case-control study in a clinical trial designed to investigate hypertension treatment in the elderly; a subsample of 50 dementia cases and 223 controls was selected. The study showed that

\section{Carotid intima-media thickness for the CT, HNCD and HCD groups}

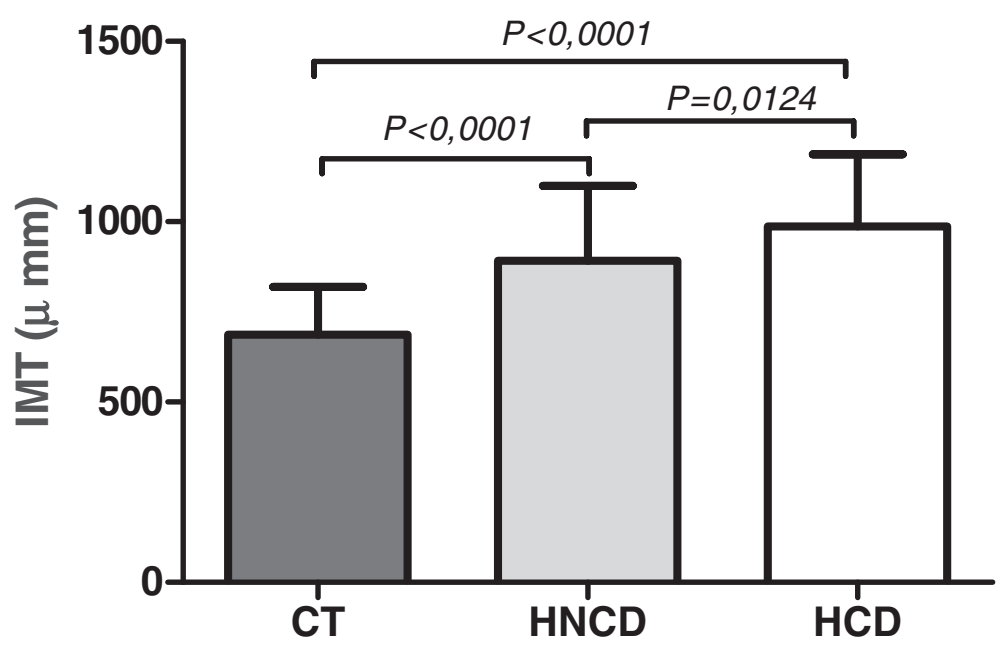

Figure 3 Evaluation of the carotid intima-media thickness for the CT, HNCD and HCD groups. IMT = carotid intima-media thickness; $C T$ - controls; $\mathrm{HNCD}=$ arterial hypertension without cognitive deficiency; $\mathrm{HCD}=$ arterial hypertension with cognitive deficiency. 
Table 6 Central systolic blood pressure and Augmentation Index with correction for a mean heart rate of 75 beats per minute

\begin{tabular}{llccc}
\hline Group & & Mean & SD & 95\% Cl \\
\hline CT & CSBP $(\mathbf{m m H g})$ & 103.6 & 18.99 & $80.93-90.50$ \\
\cline { 2 - 5 } & Ai $\mathbf{7 5}(\mathbf{m m H g})$ & 85.11 & 15.96 & $80.48-89.75$ \\
\hline HNCD & CSBP $(\mathbf{m m H g})$ & 118.8 & 15.99 & $15.6-121.9$ \\
\cline { 2 - 5 } & Ai $\mathbf{7 5}(\mathbf{m m H g})$ & 88.85 & 9.77 & $86.93-90.77$ \\
\hline HCD & CSBP $(\mathbf{m m H g})$ & 120.9 & 28.56 & $111.5-130.3$ \\
\cline { 2 - 5 } & Ai $\mathbf{7 5}(\mathbf{m m H g})$ & 89.04 & 17.15 & $86.28-94.68$ \\
\hline
\end{tabular}

$H C D$ hypertensive with cognitive deficiency, $H N C D$ hypertensive without cognitive deficiency, CT controls, CSBP central systolic blood pressure, Ai 75 Augmentation Index at 75 beats per minute.

systolic hypertension, without increases in the DBP, was identified as a risk factor for dementia. Launer et al. [80] identified an $8 \%$ increase in the risk of $\mathrm{CD}$ for each $10 \mathrm{mmHg}$ increase in SBP among 3,735 Japanese Americans. Freidl et al. [81], studying a sample of 1927 healthy elderly in the United States, found among the 16 sociodemographic, environmental and behavioral factors investigated that only age and the presence of hypertension were associated with impaired cognitive performance. Our study also showed that age was significantly associated with a decline in the MMSE scores irrespective of BP, biochemical markers and anthropometric variables.

Scuteri et al. demonstrated the role of vascular health in determining cognitive function in older individuals using multiple regression models and showed that arterial stiffness was a strong predictor of loss of cognitive function independent of age, gender, education and traditional cardiovascular risk factors [82].

Similarly, vascular remodeling detected by estimating the carotid IMT has been linked to increased risk of cardiovascular, coronary and brain events; this represents an important step in carotid plaque formation and progression and is a characteristic marker of atherosclerosis. [83-85]. Of the different pathophysiological explanations, an association between increased IMT and greater pressure variations found in hypertensive patients with vascular remodeling has been described [86]. On the other hand, Forman et al. reported that endothelial-dependent and endothelial-independent vascular responsiveness was correlated with neurocognitive performance among older cardiovascular disease patients, particularly in respect to the attention-executive domain. [87]

With clinical observation, there is a non-consensual understanding that the different forms of hypertension and the results of complications in target organs, related to stiffening of the vascular wall and atherosclerotic plaque formation among other things, are associated to micro- and macro-infarcts of the white substance and is an important causal agent of CD $[60,76,88,89]$. However, there are few studies in the literature on the association of vascular structural alterations and $\mathrm{CD}$. The results of the current study demonstrate that structural alterations characterized by increased carotid IMT are significantly associated with hypertension in the hypertensive group with $\mathrm{CD}$ when compared to hypertensive patients

\section{Central systolic blood pressure of the HCD, HNCD and CT groups}

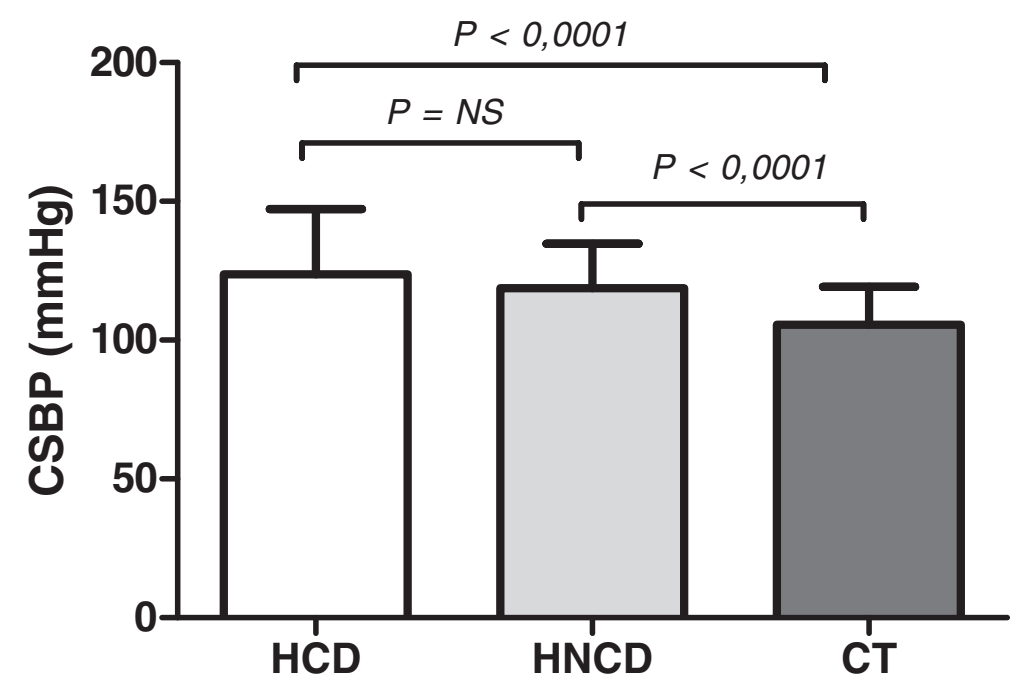

Figure 4 Central systolic blood pressure for the HCD, HNCD and CT groups. CSBP = central systolic blood pressure; $H C D=$ arterial hypertension with cognitive deficiency; HNCD = arterial hypertension without cognitive deficiency and $C T=$ controls. 
without $\mathrm{CD}$ and the $\mathrm{CT}$ group and may provide additional information to conventional risk factors for cognitive dysfunction.

There are also few publications in the literature regarding functional hemodynamic changes in hypertensive patients with $\mathrm{CD}$. Our study shows that hypertensive patients, both with and without $\mathrm{CD}$, have significantly higher CSBP compared to the CT group. However, there was no statistically significant difference in the CSBPs of hypertensive patients with and without CD.

There were no statistically significant differences for the Augmentation Index corrected for HR between the three groups (HCD, HNCD and CT).

Several hypotheses may explain the absence of significant differences between hypertensive patients with and without $\mathrm{CD}$. Antihypertensive therapy using reninangiotensin-aldosterone blockers and calcium channel blockers interferes in the hemodynamics of arterial, central and peripheral BP thus favoring a reduction in the height of the central pressure wave, thereby reducing the Augmentation Index and the central SBP. However, this does not invalidate the important structural finding represented by the main alteration found in the hypertensive group with $\mathrm{CD}$; vascular remodeling characterized by increased carotid IMT.

Potentially confounding effects of antihypertensive therapy on vascular structural and hemodynamic changes may influence cognitive function. In this study the antihypertensive medication did not influence the results (specifically beta-blockers, ACE inhibitors, ARBs and calcium channel blockers).

This study has some limitations: the results are based on a cross-sectional study and so a longitudinal approach is needed to confirm the influence of age on results. Additionally we cannot exclude the influence of genetic factors on the pathophysiology of $\mathrm{CD}$ in hypertensive patients. However, new opportunities for structural and functional hemodynamic evaluations are presented for prospective studies on hypertensive patients who have risk factors for $C D$ which may reinforce the importance of achieving the goal in the treatment of hypercholesterolemia in high-risk patients to prevent $\mathrm{CD}$.

\section{Conclusions}

Hypertensive patients with $C D$ have vascular morphological changes characterized by increased carotid IMT, enhanced atherosclerotic lipid profile and impaired hemodynamic functional manifested by elevated central systolic blood pressure.

\section{Competing interests}

The authors declare that they have no competing interests.

\section{Authors' contributions}

EMD: participated in the study design, clinical assessment of participants, ultrasound examinations, participated in the discussion of the results and helped to write the manuscript. LTG Jr: participated of the clinical

assessment of participants, measurement of the central blood pressure and in the discussion of the results.DDM: participated in the collection of clinica data, the blinded measurement of the ultrasound examinations and helped to draft the manuscript. CM: participated in data collection, assessments of peripheral blood pressure and the central blood pressure examination and elaborated the figures. HM Jr: participated of the study design, assessment of the methodology, blinded evaluation of ultrasound examinations and helped with the final discussion. JFVM: participated in the clinical assessment of patients and participated in the discussion of the results. JCYT: participated of the study design, methodological assessment, statistical review, discussion of the results and helped to write the manuscript, corrected the final version in English and submitted the article. All authors read and approved the final manuscript.

\section{Author details}

${ }^{1}$ Hypertension Clinic, Department of Internal Medicine, State Medical School of São José do Rio Preto (FAMERP), Rua: Las Vegas 200, São José do Rio Preto, SP CEP 15093-010, Brazil. ${ }^{2}$ Cardiovascular Pharmacology Laboratory, Faculty of Medical Sciences, State University of Campinas (UNICAMP), Campinas, SP CEP 13414-093, Brazil.

Received: 13 December 2011 Accepted: 18 September 2012 Published: 18 October 2012

\section{References}

1. Kannel WB: Office assessment of coronary candidates and risk factor insights from the Framingham study. J Hypertens Supp/ 1991, 9(7):S13-S19.

2. Kannel WB: Hypertension as a risk factor for cardiac eventsepidemiologic results of long-term studies. J Cardiovasc Pharmacol 1993, 21(Suppl 2):S27-S37.

3. Kannel WB: Framingham study insights into hypertensive risk of cardiovascular disease. Hypertens Res 1995, 18(3):181-196.

4. Kannel WB, Levy D, Cupples LA: Left ventricular hypertrophy and risk of cardiac failure: insights from the Framingham Study. J CardiovasC Pharmacol 1987, 10(Suppl 6):S135-S140.

5. Levy D, Larson MG, Vasan RS, Kannel WB, Ho KK: The progression from hypertension to congestive heart failure. JAMA 1996, 275(20):1557-1562.

6. Haider AW, Larson MG, Franklin SS, Levy D: Systolic blood pressure, diastolic blood pressure, and pulse pressure as predictors of risk for congestive heart failure in the Framingham Heart Study. Ann Intern Med 2003, 138(1):10-16.

7. Wilson SK, Hutchins GM: Aortic dissecting aneurysms: causative factors in 204 subjects. Arch Pathol Lab Med 1982, 106(4):175-180.

8. Crawford ES: The diagnosis and management of aortic dissection. JAMA 1990, 264(19):2537-2541.

9. Coard KC, Didier M: Aortic dissection. An autopsy experience. West Indian Med J 1990, 39(2):80-85.

10. Veriava Y, du Toit E, Lawley CG, Milne FJ, Reinach SG: Hypertension as a cause of end-stage renal failure in South Africa. J Hum Hypertens 1990 4(4):379-383.

11. Mailloux LU: Hypertension in chronic renal failure and ESRD: prevalence, pathophysiology, and outcomes. Semin Nephrol 2001, 21(2):146-156.

12. Zoccali C, Mallamaci F, Tripepi G: Hypertension as a cardiovascular risk factor in end-stage renal failure. Curr Hypertens Rep 2002, 4(5):381-386.

13. Karthikeyan VJ, Lip GY: Peripheral artery disease and hypertension: the relation between ankle-brachial index and mortality. $J$ Hum Hypertens 2007, 21(10):762-765.

14. Kannel WB: Blood pressure as a cardiovascular risk factor: prevention and treatment. JAMA 1996, 275(20):1571-1576.

15. Kannel WB: Historic perspectives on the relative contributions of diastolic and systolic blood pressure elevation to cardiovascular risk profile. Am Heart J 1999, 138(3 Pt 2):205-210.

16. Plouin PF, Rossignol P, Bobrie G: Hypertension in the elderly. Bull Acad Nat/ Med 2006, 190(4-5):793-805. discussion 6, 73-6.

17. Patterson CJ, Gauthier S, Bergman H, Cohen CA, Feightner JW, Feldman H, et al: Canadian Consensus Conference on Dementia: a physician's guide to using the recommendations. CMAJ 1999, 160(12):1738-1742. 
18. Fritsch T, McClendon MJ, Smyth KA, Lerner AJ, Friedland RP, Larsen JD: Cognitive functioning in healthy aging: the role of reserve and lifestyle factors early in life. Gerontologist 2007, 47(3):307-322.

19. Farmer ME, White LR, Abbott RD, Kittner SJ, Kaplan E, Wolz MM, et al: Blood pressure and cognitive performance. The Framingham Study. Am J Epidemiol 1987, 126(6):1103-1114.

20. Duron $E$, Hanon $O$ : Hypertension, cognitive decline and dementia. Arch Cardiovasc Dis 2008, 101(3):181-189.

21. Scheinberg P: Dementia due to vascular disease-a multifactorial disorder. Stroke 1988, 19(10):1291-1299.

22. Dozono K, Ishii N, Nishihara $Y$, Horie A: An autopsy study of the incidence of lacunes in relation to age, hypertension, and arteriosclerosis. Stroke 1991, 22(8):993-996

23. Chui HC: Subcortical ischemic vascular dementia. Neurol Clin 2007, 25(3):717-740. vi.

24. Obisesan TO: Hypertension and cognitive function. Clin Geriatr Med 2009, 25(2):259-288

25. Prins ND, van Dijk EJ, den Heijer T, Vermeer SE, Koudstaal PJ, Oudkerk M, et al: Cerebral white matter lesions and the risk of dementia. Arch Neurol 2004, 61(10):1531-1534.

26. Gunstad J, Cohen RA, Tate DF, Paul RH, Poppas A, Hoth K, et al: Blood pressure variability and white matter hyperintensities in older adults with cardiovascular disease. Blood Press 2005, 14(6):353-358.

27. Au R, Massaro JM, Wolf PA, Young ME, Beiser A, Seshadri S, et al: Association of white matter hyperintensity volume with decreased cognitive functioning: the Framingham Heart Study. Arch Neurol 2006, 63(2):246-250.

28. Debette S, Bombois S, Bruandet A, Delbeuck X, Lepoittevin S, Delmaire C, et al: Subcortical hyperintensities are associated with cognitive decline in patients with mild cognitive impairment. Stroke 2007, 38(11):2924-2930.

29. Chen F, Suzuki Y, Nagai N, Jin L, Yu J, Wang H, et al: Rodent stroke induced by photochemical occlusion of proximal middle cerebral artery: evolution monitored with MR imaging and histopathology. Eur J Radiol 2007, 63(1):68-75.

30. Duron $\mathrm{E}$, Hanon $\mathrm{O}$ : Vascular risk factors, cognitive decline, and dementia. Vasc Health Risk Manag 2008, 4(2):363-381.

31. Starr JM, Whalley $L$, Inch $S$, Shering PA: Blood pressure and cognitive function in healthy old people. J Am Geriatr Soc 1993, 41(7):753-756.

32. Prince $M$, Cullen M, Mann A: Risk factors for Alzheimer's disease and dementia: a case-control study based on the MRC elderly hypertension trial. Neurology 1994, 44(1):97-104.

33. in't Veld BA, Ruitenberg A, Hofman A, Stricker BH, Breteler MM: Antihypertensive drugs and incidence of dementia: the Rotterdam Study. Neurobiol Aging 2001, 22(3):407-412.

34. Efimova N, Chernov VI, Efimova I, Afanas'eva NL, Lishmanov IB: Cognitive dysfunction and brain perfusion in patients with arterial hypertension: possibilities of pharmacological therapy. Zh Nevrol Psikhiatr Im S S Korsakova 2008, 108(11):10-15.

35. Elias MF, Wolf PA, D'Agostino RB, Cobb J, White LR: Untreated blood pressure level is inversely related to cognitive functioning: the Framingham Study. Am J Epidemiol 1993, 138(6):353-364.

36. Forette F, Seux ML, Staessen JA, Thijs L, Babarskiene MR, Babeanu S, et al: The prevention of dementia with antihypertensive treatment: new evidence from the Systolic Hypertension in Europe (Syst-Eur) study. Arch Intern Med 2002, 162(18):2046-2052.

37. Tzourio C, Anderson C, Chapman N, Woodward M, Neal B, MacMahon S, et al: Effects of blood pressure lowering with perindopril and indapamide therapy on dementia and cognitive decline in patients with cerebrovascular disease. Arch Intern Med 2003, 163(9):1069-1075.

38. Lithell H, Hansson L, Skoog I, Elmfeldt D, Hofman A, Olofsson B, et al: The Study on Cognition and Prognosis in the Elderly (SCOPE): principal results of a randomized double-blind intervention trial. J Hypertens 2003, 21(5):875-886

39. Chobanian AV, Bakris GL, Black HR, Cushman WC, Green LA, Izzo JL Jr, et al: The Seventh Report of the Joint National Committee on Prevention, Detection, Evaluation, and Treatment of High Blood Pressure: the JNC 7 report. JAMA 2003, 289(19):2560-2572.

40. Al-Azzam SI, Najjar RB, Khader YS: Awareness of physicians in Jordan about the treatment of high blood pressure according to the seventh report of the Joint National Committee (JNC VII). Eur J CardiovasC Nurs 2007, 6(3):223-232
41. Bertolucci PH, Brucki SM, Campacci SR, Juliano Y: The Mini-Mental State Examination in a general population: impact of educational status. Arq Neuropsiquiatr 1994, 52(1):1-7.

42. Brucki SM, Nitrini R, Caramelli P, Bertolucci PH, Okamoto $\mathbb{H}$ : Suggestions for utilization of the mini-mental state examination in Brazil. Arq Neuropsiquiatr 2003, 61(3B):777-781.

43. Brucki SM, Rocha MS: Category fluency test: effects of age, gender and education on total scores, clustering and switching in Brazilian Portuguese-speaking subjects. Braz J Med Biol Res 2004, 37(12):1771-1777.

44. Cullen B, O'Neill B, Evans JJ, Coen RF, Lawlor BA: A review of screening tests for cognitive impairment. J Neurol Neurosurg Psychiatry 2007, 78(8):790-799.

45. Ladeira RB, Diniz BS, Nunes PV, Forlenza OV: Combining cognitive screening tests for the evaluation of mild cognitive impairment in the elderly. Clinics (Sao Paulo) 2009, 64(10):967-973.

46. Haubois G, Annweiler C, Launay C, Fantino B, de Decker L, Allali G, et al: Development of a short form of Mini-Mental State Examination for the screening of dementia in older adults with a memory complaint: a case control study. BMC Geriatr 2011, 11:59.

47. Redberg RF, Vogel RA, Criqui MH, Herrington DM, Lima JA, Roman MJ: 34th Bethesda Conference: Task force \#3-What is the spectrum of current and emerging techniques for the noninvasive measurement of atherosclerosis? J Am Coll Cardiol 2003, 41(11):1886-1898.

48. Stein JH, Korcarz CE, Hurst RT, Lonn E, Kendall CB, Mohler ER, et al: Use of carotid ultrasound to identify subclinical vascular disease and evaluate cardiovascular disease risk: a consensus statement from the American Society of Echocardiography Carotid Intima-Media Thickness Task Force. Endorsed by the Society for Vascular Medicine. J Am Soc Echocardiogr 2008, 21(2):89-90.

49. Yugar-Toledo JC, Bonalume Tacito LH, Ferreira-Melo SE, Sousa W, Consolin-Colombo F, Irigoyen MC, et al: Low-renin (volume dependent) mild-hypertensive patients have impaired flow-mediated and glyceryl-trinitrate stimulated vascular reactivity. Circ J 2005, 69(11):1380-1385.

50. Lonn E, Suppl A: Use of carotid ultrasound to stratify risk. Can J Cardiol 2001, Suppl A:22A-25A.

51. Nelson MR, Stepanek J, Cevette M, Covalciuc M, Hurst RT, Tajik AJ: Noninvasive measurement of central vascular pressures with arterial tonometry: clinical revival of the pulse pressure waveform? Mayo Clin Proc 2010, 85(5):460-472

52. Roman MJ, Devereux RB, Kizer JR, Lee ET, Galloway JM, Ali T, et al: Central pressure more strongly relates to vascular disease and outcome than does brachial pressure: the Strong Heart Study. Hypertension 2007, 50(1):197-203

53. Agabiti-Rosei E, Mancia G, O'Rourke MF, Roman MJ, Safar ME, Smulyan H, et al: Central blood pressure measurements and antihypertensive therapy: a consensus document. Hypertension 2007, 50(1):154-160.

54. Laurent S, Cockcroft J, Van Bortel L, Boutouyrie P, Giannattasio C, Hayoz D, et al: Expert consensus document on arterial stiffness: methodological issues and clinical applications. Eur Heart J 2006, 27(21):2588-2605.

55. O'Rourke MF, Adji A: An updated clinical primer on large artery mechanics: implications of pulse waveform analysis and arterial tonometry. Curr Opin Cardiol 2005, 20(4):275-281.

56. O'Rourke MF, Seward JB: Central arterial pressure and arterial pressure pulse: new views entering the second century after Korotkov. Mayo Clin Proc 2006, 81(8):1057-1068.

57. Lowe A, Harrison W, El-Aklouk E, Ruygrok P, Al-Jumaily AM: Non-invasive model-based estimation of aortic pulse pressure using suprasystolic brachial pressure waveforms. J Biomech 2009, 42(13):2111-2115.

58. Avolio AP, Butlin M, Walsh A: Arterial blood pressure measurement and pulse wave analysis-their role in enhancing cardiovascular assessment. Physiol Meas 2010, 31(1):R1-R47.

59. Inouye SK, Albert MS, Mohs R, Sun K, Berkman LF: Cognitive performance in a high-functioning community-dwelling elderly population. $J$ Gerontol 1993, 48(4):M146-M151.

60. Fratiglioni L, Grut M, Forsell Y, Viitanen M, Grafstrom M, Holmen K, et al: Prevalence of Alzheimer's disease and other dementias in an elderly urban population: relationship with age, sex, and education. Neurology 1991, 41(12):1886-1892.

61. Sulkava R, Erkinjuntti T, Palo J: Head injuries in Alzheimer's disease and vascular dementia. Neurology 1985, 35(12):1804. 
62. Jin H, Zhang MY, Qu OY, Wang ZY, Salmon DP, Katzman R, et al: Cross-cultural studies of dementia: use of a Chinese version of the Blessed-Roth Information-Memory-Concentration test in a Shanghai dementia survey. Psychol Aging 1989, 4(4):471-479.

63. Katzman DA: Medical education in the United States: a century of change. JAMA 1989, 261(13):1975-1978.

64. Katzman R, Aronson M, Fuld P, Kawas C, Brown T, Morgenstern H, et al: Development of dementing illnesses in an 80-year-old volunteer cohort. Ann Neurol 1989, 25(4):317-324.

65. Berkman LF: The association between educational attainment and mental status examinations: of etiologic significance for senile dementias or not? J Chronic Dis 1986, 39(3):171-175.

66. Kokmen E, Ozsarfati Y, Beard CM, O'Brien PC, Rocca WA: Impact of referral bias on clinical and epidemiological studies of Alzheimer's disease. J Clin Epidemiol 1996, 49(1):79-83.

67. Petrova M, Prokopenko S, Pronina E, Mozheyko E: Diabetes type 2, hypertension and cognitive dysfunction in middle age women. $J$ Neurol Sci 2010, 299(1-2):39-41.

68. Shaji S, Promodu K, Abraham T, Roy KJ, Verghese A: An epidemiological study of dementia in a rural community in Kerala, India. Br J Psychiatry 1996, 168(6):745-749.

69. Tangalos EG, Smith GE, Ivnik RJ, Petersen RC, Kokmen E, Kurland LT, et al: The Mini-Mental State Examination in general medical practice: clinical utility and acceptance. Mayo Clin Proc 1996, 71(9):829-837.

70. Umegaki H: Pathophysiology of cognitive dysfunction in older people with type 2 diabetes: vascular changes or neurodegeneration? Age Ageing 2010, 39(1):8-10.

71. Preobrazhenskaia IS, lakhno NN: [Cognitive dysfunction in elderly patients: diagnosis and treatment]. Zh Nevrol Psikhiatr Im S S Korsakova 2006, 106(11):33-38.

72. Patterson CJ, Gauthier S, Bergman H, Cohen CA, Feightner JW, Feldman H, et al: The recognition, assessment and management of dementing disorders: conclusions from the Canadian Consensus Conference on Dementia. CMAJ 1999, 160(12 Suppl):S1-S15.

73. Inouye SK, Acampora D, Miller RL, Fulmer T, Hurst LD, Cooney LM Jr: The Yale Geriatric Care Program: a model of care to prevent functional decline in hospitalized elderly patients. J Am Geriatr Soc 1993, 41(12):1345-1352.

74. Chertkow H: Diagnosis and treatment of dementia: introduction. Introducing a series based on the Third Canadian Consensus Conference on the Diagnosis and Treatment of Dementia. CMAJ 2008, 178(3):316-321.

75. Ikeda N, Kogame N, lijima R, Nakamura M, Sugi K: Carotid artery intimamedia thickness and plaque score can predict the SYNTAX score. Eur Heart J 2012, 33(1):113-119.

76. Breteler MM, van Amerongen NM, van Swieten JC, Claus JJ, Grobbee DE, van Gijn J, et al: Cognitive correlates of ventricular enlargement and cerebral white matter lesions on magnetic resonance imaging. The Rotterdam Study. Stroke 1994, 25(6):1109-1115.

77. Crum RM, Anthony JC, Bassett SS, Folstein MF: Population-based norms for the Mini-Mental State Examination by age and educational level. JAMA 1993, 269(18):2386-2391.

78. Brayne C, Beardsall L: Estimation of verbal intelligence in an elderly community: an epidemiological study using NART. Br J Clin Psychol 1990, 29(Pt 2):217-223.

79. Liao D, Cooper L, Cai J, Toole J, Bryan N, Burke G, et al: The prevalence and severity of white matter lesions, their relationship with age, ethnicity, gender, and cardiovascular disease risk factors: the ARIC Study. Neuroepidemiology 1997, 16(3):149-162.

80. Launer LJ, Masaki K, Petrovitch H, Foley D, Havlik RJ: The association between midlife blood pressure levels and late-life cognitive function. The Honolulu-Asia Aging Study. JAMA 1995, 274(23):1846-1851.

81. Freidl W, Schmidt R, Stronegger WJ, Irmler A, Reinhart B, Koch M: Mini mental state examination: influence of sociodemographic, environmental and behavioral factors and vascular risk factors. J Clin Epidemiol 1996, 49(1):73-78.

82. Scuteri A, Tesauro M, Appolloni S, Preziosi F, Brancati AM, Volpe M: Arterial stiffness as an independent predictor of longitudinal changes in cognitive function in the older individual. $J$ Hypertens 2007 25(5):1035-1040

83. Baldassarre D, Tremoli E, Amato M, Veglia F, Bondioli A, Sirtori CR: Reproducibility validation study comparing analog and digital imaging technologies for the measurement of intima-media thickness. Stroke 2000, 31(5):1104-1110.

84. Hollander M, Koudstaal PJ, Bots ML, Grobbee DE, Hofman A, Breteler MM: Incidence, risk, and case fatality of first ever stroke in the elderly population. The Rotterdam Study. J Neurol Neurosurg Psychiatry 2003, 74(3):317-321.

85. Simon A, Gariepy J, Chironi G, Megnien JL, Levenson J: Intima-media thickness: a new tool for diagnosis and treatment of cardiovascular risk. $J$ Hypertens 2002, 20(2):159-169.

86. Mancia G, Parati G, Hennig M, Flatau B, Omboni S, Glavina F, et al: Relation between blood pressure variability and carotid artery damage in hypertension: baseline data from the European Lacidipine Study on Atherosclerosis (ELSA). J Hypertens 2001, 19(11):1981-1989.

87. Forman DE, Cohen RA, Hoth KF, Haley AP, Poppas A, Moser DJ, et al: Vascular Health and Cognitive Function in Older Adults with Cardiovascular Disease. Artery Res 2008, 2(1):35-43.

88. Desmond DW, Tatemichi TK, Paik M, Stern Y: Risk factors for cerebrovascular disease as correlates of cognitive function in a stroke-free cohort. Arch Neurol 1993, 50(2):162-166.

89. Kokmen E, Whisnant JP, O'Fallon WM, Chu CP, Beard CM: Dementia after ischemic stroke: a population-based study in Rochester, Minnesota (1960-1984). Neurology 1996, 46(1):154-159.

doi:10.1186/1476-7120-10-41

Cite this article as: Dias et al:: Carotid intima-media thickness is associated with cognitive deficiency in hypertensive patients with elevated central systolic blood pressure. Cardiovascular Ultrasound 2012 $10: 41$.

\section{Submit your next manuscript to BioMed Central and take full advantage of:}

- Convenient online submission

- Thorough peer review

- No space constraints or color figure charges

- Immediate publication on acceptance

- Inclusion in PubMed, CAS, Scopus and Google Scholar

- Research which is freely available for redistribution 